\title{
Gastrin responses in patients with adrenergic insufficiency
}

\author{
R J POLINSKY,* I L TAYLOR, $\dagger$ V WEISE, $\ddagger$ I J KOPIN $\ddagger$ \\ From the Clinical Neuropharmacology Section,* Medical Neurology Branch, and the Immunopharmacology \\ Section, $\ddagger$ Neuroimmunology Branch, N.I.N.C.D.S., Bethesda, MD and Duke University Medical Center $\dagger$, \\ Durham, NC, USA
}

SUMMARY High basal gastrin levels in pure autonomic failure could result from peripheral vagus nerve involvement, whereas the increased response during hypoglycaemia may reflect adrenergic supersensitivity. A reduced gastrin increment in multiple system atrophy was found following insulin-hypoglycaemia and is consistent with decreased gastrin release secondary to diminished central sympathetic nervous system activation in the absence of peripheral denervation supersensitivity.

Chronic autonomic failure is attended by a variety of abnormal biochemical, pharmacological, and hormonal responses. ${ }^{1}$ Although the symptoms of autonomic dysfunction are quite similar, central neurological signs such as ataxia, rigidity and bradykinesia distinguish patients who have multiple system atrophy with autonomic failure from those who have isolated or pure autonomic failure (idiopathic orthostatic hypotension). Biochemical and pharmacological assessments of autonomic function also differentiate multiple system atrophy from idiopathic orthostatic hypotension. In both multiple system atrophy and idiopathic orthostatic hypotension, plasma norepinephrine levels fail to increase upon standing; however, the supine norepinephrine level is low only in patients with idiopathic orthostatic hypotension. ${ }^{2}$ In multiple system atrophy, an otherwise intact peripheral sympathetic nervous system appears not to be appropriately activated whereas in idiopathic orthostatic hypotension this portion of the nervous system seems to be directly involved. This distinction is further supported by investigations of pressor sensitivity ${ }^{3}$ and neuronal uptake of norepinephrine. $^{4}$ Diminished or absent epinephrine ${ }^{56}$ and pancreatic polypeptide ${ }^{7}$ responses to insulin-induced hypoglycaemia indicate that the pandysautonomia

Address for reprint requests: Ronald J Polinsky, M.D., National Institutes of Health, Building 10, Room 5N236, 9000 Rockville Pike, Bethesda, Maryland 20892, USA.

Received 18 March 1987 and in revised form 16 July 1987. Accepted 20 July 1987. may also affect adrenal medullary or parasympathetic function.

Gastrointestinal dysfunction caused by autonomic failure can have serious practical and medical consequences as exemplified by gastroparesis diabeticorum. ${ }^{8}$ Two major factors that affect digestion in the stomach are motility and acid secretion. ${ }^{9}$ The control mechanisms for gastrin release are complex, with stimulatory and inhibitory components. Investigation of gastrin responses in patients with chronic autonomic failure might elucidate the role of the autonomic nervous system in regulating gastrin secretion. Assessment of gastrin responses might also provide some insight into the symptoms related to impaired gastric function in autonomic failure. We therefore examined plasma gastrin and catecholamine responses during insulininduced hypoglycaemia in 13 control subjects, 10 idiopathic orthostatic hypotension and nine multiple system atrophy patients.

\section{Methods}

All subjects were admitted to the Clinical Center, National Institutes of Health (NIH) for the study. Thirteen control subjects (seven men, six women) ranging in age from 22 to 69 years volunteered for this study through the NIH Normal Volunteer Program. Patients were admitted for evaluation and treatment of orthostatic hypotension. The diagnosis of multiple system atrophy and idiopathic orthostatic hypotension was made according to previously published criteria. ${ }^{5}$ The table summarises the clinical characteristics of the patients who participated in this study. Routine blood studies, electrocardiogram, chest radiography, and a detailed medical examination were performed prior to 
Table Clinical characteristics of patients with autonomic function

\begin{tabular}{|c|c|c|c|c|}
\hline \multirow[b]{2}{*}{$\begin{array}{l}\text { Patient } \\
\text { No. }\end{array}$} & \multicolumn{4}{|c|}{ Clinical characteristics of patients } \\
\hline & $\begin{array}{l}\text { Age } \\
(y r)\end{array}$ & Sex & Diagnosis & $\begin{array}{l}\text { Duration of } \\
\text { Symptoms }(y r)\end{array}$ \\
\hline 1 & 64 & F & $\mathrm{IOH}$ & 2 \\
\hline 2 & 32 & $\mathrm{~F}$ & $\mathrm{IOH}$ & 3 \\
\hline 3 & 72 & $\mathbf{M}$ & $\mathrm{IOH}$ & 12 \\
\hline 4 & 54 & $F$ & $\mathrm{IOH}$ & 13 \\
\hline 5 & 70 & $\mathbf{M}$ & $\mathrm{IOH}$ & 6 \\
\hline 6 & 73 & $\mathbf{M}$ & $\mathrm{IOH}$ & 13 \\
\hline 7 & 65 & $\mathbf{M}$ & $\mathrm{IOH}$ & 8 \\
\hline 8 & 40 & F & $\mathrm{IOH}$ & 5 \\
\hline 9 & 66 & $\mathbf{M}$ & $\mathrm{IOH}$ & 9 \\
\hline 10 & 69 & F & $\mathrm{IOH}$ & 8 \\
\hline 11 & 53 & $\mathbf{M}$ & MSA & 5 \\
\hline 12 & 52 & $\mathbf{M}$ & MSA & 5 \\
\hline 13 & 55 & $\mathbf{M}$ & MSA & 4 \\
\hline 14 & 54 & $\mathbf{M}$ & MSA & 6 \\
\hline 15 & 63 & $\mathbf{M}$ & MSA & 10 \\
\hline 16 & 55 & $\mathbf{M}$ & MSA & 3 \\
\hline 17 & 38 & $\mathbf{M}$ & MSA & 2 \\
\hline 18 & 51 & $\mathrm{~F}$ & MSA & 6 \\
\hline 19 & 49 & $\mathbf{M}$ & MSA & 3 \\
\hline
\end{tabular}

initiating any investigations. Informed consent was obtained from all subjects in accordance with NIH guidelines. There were no special dietary restrictions. Patients were asked to discontinue all medications for a minimum of 1 week before the insulin tolerance test.

\section{Insulin Tolerance Test}

After an overnight fast, a 19 gauge butterfly needle was inserted into the antecubital vein of one arm for blood sampling. A slow infusion of $0.45 \%$ saline was given to maintain patency of an intravenous catheter placed in a forearm vein of the opposite upper extremity. All subjects remained supine during the test. A minimum of 20 minutes elapsed before baseline blood samples were taken. Blood was sampled at $10,20,30,35,40,45,50,55,60,75,90$, and 120 minutes after an intravenous bolus injection of regular insulin $(0 \cdot 15 \mathrm{U} / \mathrm{kg})$. The typical signs of hypoglycaemia including diaphoresis, pallor, tachycardia, fatigue, drowsiness, and nervousness were less prominent in the patients. It was not necessary in any subject to treat the hypoglycaemia with glucose.

\section{Plasma Glucose Assay}

A conventional glucose oxidase $\operatorname{method}^{10}$ was used to measure the plasma glucose concentration in specimens drawn into tubes containing fluoride-oxalate anticoagulant.

\section{Plasma Catecholamine Analysis}

A previously described radioenzymatic assay ${ }^{10-13}$ was used to determine plasma norepinephrine (NE) and epinephrine (EPI) levels. After removal of proteins, catecholamines were O-methylated by incubation with catechol-O-methyl transferase and tritiated S-adenosyl methionine. ${ }^{13}$ Borate buffer (pH 10) containing unlabelled metanephrine and normetanephrine was added to stop the reaction. The amines were extracted into toluene-iso-amyl alcohol $(3: 2)$, then into $0.1 \mathrm{M}$ acetic acid, and the radioactive products were separated by thin layer chromatography. ${ }^{12}$ After periodate oxidation of the separated $\mathrm{O}$-methylated compounds
Polinsky, Taylor, Weise, Kopin

to vanillin, phosphor-containing toluene was added to determine the tritium content by liquid scintillation spectrometry. $\bar{Q}$ Known amounts of the catecholamines were used as internal standards to determine the factors for conversion of tritium to quantities of the amines. This assay adequately measures $10 \mathrm{pg}$ catecholamine $/ \mathrm{ml}$ plasma with an interassay variation of less than $10 \%$.

\section{Gastrin Measurement}

Blood was collected in tubes containing acid-citrate-dextrose $(0.5 \mathrm{ml}$ per $4.5 \mathrm{ml}$ of whole blood). The plasma was removed. after the samples were centrifuged. All plasma samples were $\overrightarrow{\vec{F}}$ stored at $-70^{\circ} \mathrm{C}$ until the time of assay. Gastrin concen- $\stackrel{0}{\rightarrow}$ trations were measured by radioimmunoassay according to $\bar{C}$ published methods using Ab $1296 .{ }^{14}$ This is a carboxyl- 음 terminal specific antiserum which measures both major $\frac{\bar{\omega}}{\mathrm{D}}$ forms of circulating gastrin-G17 and G34. ${ }^{125}$ I-labelled $\mathbb{D}$ G17 was prepared by the chloramine-T method, purified by ion-exchange chromatography and the peak corresponding $\mathrm{c}$ to mono-iodinated peptide used. The detection limit of the $\vec{\circ}$ assay was $0.25 \mathrm{fmol}$ per $\mathrm{ml}$ of standard G17-I.

\section{Analysis of Data}

The average EPI and NE response in each subject during hypoglycaemia was determined as the area under the curve above the extrapolated baseline divided by the time of the $G$ interval (usually between 30 and 60 minutes after insulinto Plasma glucose, basal gastrin levels, the gastrin incremer during hypoglycaemia and catecholamine responses were compared among the three groups of subjects by analysis variance. The relationships between catecholamine ane gastrin responses were examined by linear regressiof Differences were considered statistically significant with $\mathrm{p}<0.05$.

\section{Results}

Plasma glucose dropped precipitously in normal subjects with a nadir of $20.8 \pm 2.9 \mathrm{mg} \%$ reached approximately 30 minutes following insulin administration. Similar reductions in glucose to $23.6 \pm 1.9$ and $24.2 \pm 3.7 \mathrm{mg} \%$ were observed in idiopathic orthostatic hypotension and multiple system atrophy patients respectively. The biphasic recovery curve to euglycaemia after the nadir in normal subjects has been previously reported. ${ }^{5}$ The normal initial rapid phase of glucose elevation was not evident in either patient group.

Plasma EPI and NE levels began to increase about 20 minutes after insulin injection in normal subjects; the maximum plasma catecholamine levels were reached within 5 minutes after the nadir of hypoglycaemia. Most patients with either idiopathic orthostatic hypotension or multiple system atrophy had little increase in plasma catecholamines. The mean EPI responses of $185 \cdot 2 \pm 55 \cdot 3$ and $221 \cdot 1 \pm 92 \cdot 1 \mathrm{pg} / \mathrm{ml}$ in idiopathic orthostatic hypotension and multiple system atrophy respectively were significantly less $\tilde{\sim}$ $(\mathrm{p}<0.001)$ than in normal subjects $(864.3 \pm 123$

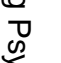




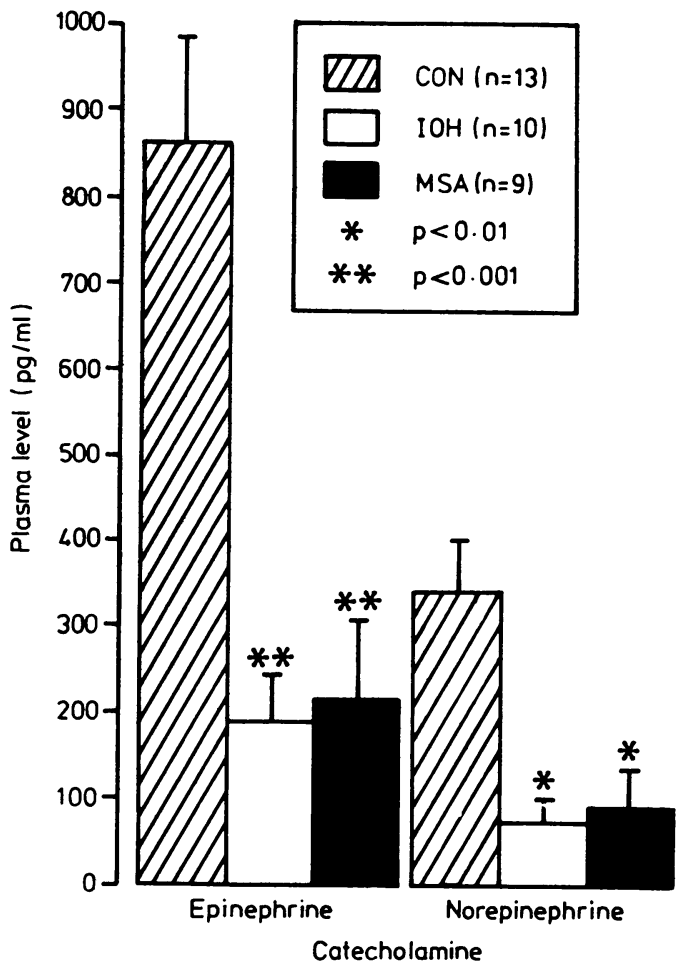

Fig 1 Mean catecholamine responses during insulininduced hypoglycaemia in control subjects (CON) and patients with either pure autonomic failure (IOH) or multiple system atrophy with autonomic failure (MSA).

$\mathrm{pg} / \mathrm{ml}$ ). A similar deficiency in NE responses was observed in both patient groups (fig 1).

Basal gastrin levels in idiopathic orthostatic hypotension patients $(125 \pm 36 \cdot 3 \mathrm{pg} / \mathrm{ml})$ were significantly greater $(\mathrm{p}<0.01)$ than in normal subjects $(27.2 \pm 1.3 \mathrm{pg} / \mathrm{ml})$ or multiple system atrophy patients $(31.3 \pm 2.9 \mathrm{pg} / \mathrm{ml})$. Gastrin levels increased in all subjects in response to hypoglycaemia. The increment in plasma gastrin during hypoglycaemia was significantly greater $(\mathrm{p}<0.05)$ in idiopathic orthostatic hypotension $(50.2 \pm 21.6 \mathrm{pg} / \mathrm{ml})$ but less $(p<0.01)$ in multiple system atrophy $(5.2 \pm 1.4 \mathrm{pg} / \mathrm{ml})$ compared with $17.7 \pm 3.4 \mathrm{pg} / \mathrm{ml}$ observed in normal subjects (fig 2 ).

There did not appear to be a significant correlation between the catecholamine responses and the gastrin increments in any group of subjects and basal gastrin levels were not related to plasma EPI or NE concentrations.

\section{Discussion}

The results of this study demonstrate that the release

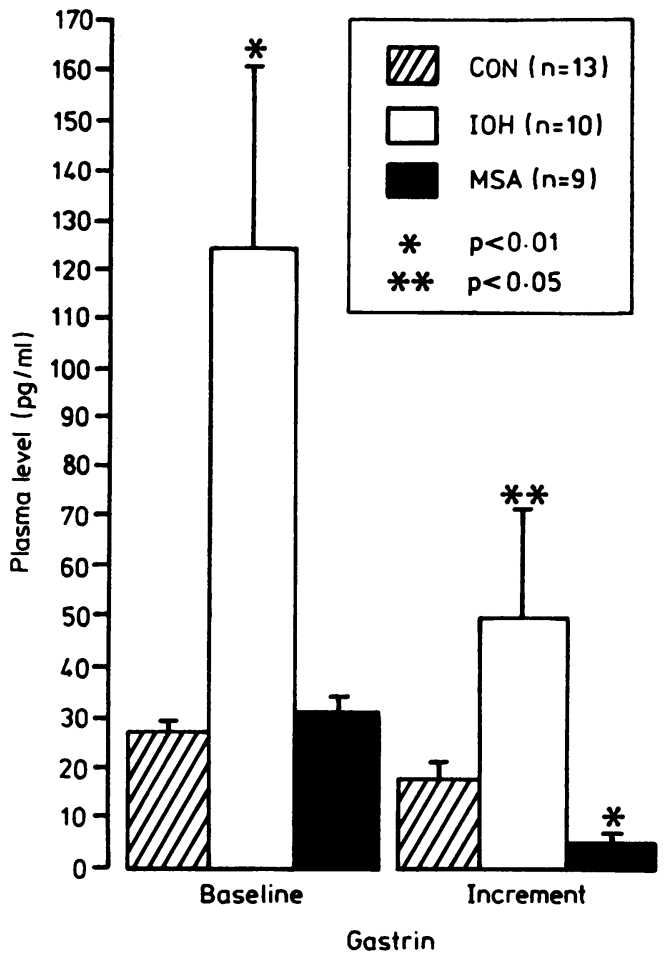

Fig 2 Baseline gastrin levels and increments during hypoglycaemia in normal subjects and patients with autonomic failure.

of gastrin is altered in patients with chronic autonomic failure. The pattern of abnormal gastrin responses in idiopathic orthostatic hypotension and multiple system atrophy may reflect differences in the site of lesion(s) causing autonomic failure in these two diseases. Increased fasting gastrin levels have been observed in duodenal ulcer patients who have undergone vagotomy ${ }^{15-18}$ and it has been suggested that vagus nerve activity inhibits gastrin release. However, under controlled experimental conditions, vagus nerve stimulation appears to release gastrin. ${ }^{19}$ Vagus nerve activation also increases gastric motility and acid secretion. Although vagotomy might directly reduce gastrin secretion, the attendant delayed gastric emptying and the increase in intragastric $\mathrm{pH}$ would be expected to elevate gastrin secretion. Thus, the high basal gastrin levels in idiopathic orthostatic hypotension patients are consistent with peripheral involvement of the vagus nerve. Hypochlorhydria is probably the major stimulus for the high gastrin levels. In fact, two patients (nos. 3 and 6) had extremely high gastrin levels; these were in the range which would be expected in subjects who are 
achlorhydric. These two patients had been ill for longer than 10 years. Acid secretory studies have not been performed because of the increased risk of aspiration in neurological patients.

Biochemical evidence for abdominal vagal involvement in idiopathic orthostatic hypotension is provided by the essentially absent pancreatic polypeptide responses to insulin-induced hypoglycaemia, since this peptide is felt to be a vagal-cholinergic marker. ${ }^{7}$ Pancreatic polypeptide responses are reduced but to a somewhat lesser degree in patients with multiple system atrophy. Cardiac vagal tone and function are also impaired in idiopathic orthostatic hypotension and multiple system atrophy; ${ }^{7}$ however, there is not good justification to assume that cardiac and gastric innervation are necessarily affected in parallel. Since there is no correlation between the acid response to modified sham feeding and the pancreatic polypeptide response, it appears that vagal tone may actually vary from organ to organ even within the abdomen. ${ }^{20}$ The peripheral and central localisation of parasympathetic lesions in idiopathic orthostatic hypotension and multiple system atrophy respectively have been inferred from the sympathetic dysfunction which has been intensively studied. ${ }^{1-4}$ Unfortunately, there has not been a complete pathological examination of an unquestionable case of idiopathic orthostatic hypotension. In contrast, numerous reports confirm multiple sites of central nervous system involvement including parasympathetic centres in multiple system atrophy (for review see reference 21).

Although insulin-induced hypoglycaemia elicits a substantial rise in plasma gastrin, the mechanism of this response is unclear. Local cholinergic reflexes, ${ }^{2223}$ increased sympathetic nervous activity, ${ }^{24}$ and release of gastrin by epinephrine ${ }^{25-27}$ have been proposed since the gastrin response persists following even highly selective vagotomy. Gastrin can be released in response to $\beta$-adrenergic stimulation by infused epinephrine. ${ }^{2829}$ Enhancement by atropine of the gastrin response during hypoglycaemia suggests that an inhibitory muscarinic cholinergic pathway might also be involved. ${ }^{23}$

Despite their similar clinical manifestations of autonomic failure, pharmacological assessment of sympathetic nervous system function differentiates idiopathic orthostatic hypotension from multiple system atrophy. ${ }^{3}$ In both conditions pressor agent dose-response curves show non-specific increases in slope consistent with a lack of baroreflex modulation of blood pressure. In idiopathic orthostatic hypotension, however, there is in addition a shift to the left of the norepinephrine dose-pressor response curve indicative of true adrenergic receptor supersensitivity. Although, as reported previously, ${ }^{5}$ both idiopathic orthostatic hypotension and multiple system atrophy patients have deficient catecholamine responses to insulin-induced hypoglycaemia, the greater gastrin response to hypoglycaemia in idiopathic orthostatic hypotension may be due to an exaggerated release of gastrin by EPI as a consequence of supersensitive adrenergic receptors. Supersensitivity of other $\beta$-adrenergic cardiovascular responses has been reported in patients with autonomic dysfunction. ${ }^{30}$ Investigation of the gastrin responses to isoproterenol, a pure beta-adrenergic agonist, is in progress to examine further the adrenergic receptor sensitivity. It is also possible that disruption of local inhibitory cholinergic pathways in idiopathic orthostatic hypotension or an impaired acid secretory response might also enhance the gastrin response to hypoglycaemia. The diminished gastrin response to hypoglycaemia in multiple system atrophy probably reflects the decreased circulating EPI response in the absence of enhanced adrenergic sensitivity-induced gastrin release. Peripheral vagal and cholinergic pathways are presumably intact in multiple system atrophy.

We did not observe a significant relationship between the gastrin increment and plasma EPIO response during hypoglycaemia as previously reported by Brandsborg et al. ${ }^{29}$ This may be due too 음 the relatively small number of control subjects. $\varrho$ Brandsborg et al. ${ }^{29}$ studied patients with duodenalo ulcer, half of whom had selective vagotomy and their results might not apply to normal subjects. Lack of correlation among the fasting gastrin levels and either basal or stimulated catecholamine increments is consistent with parasympathetic modulation of the resting gastrin levels. Direct sympathetic gastric innervation does not appear to regulate gastrin release since NE is predominantly alpha adrenergic. Although plasma NE responses do not correlate with gastrin increments, it is quite possible that antecubital venous levels of NE do not adequately reflect splanchnic or mesenteric sympathetic activity.

In summary, we have shown that chronic peripheral involvement of the autonomic nervous system in idiopathic orthostatic hypotension is associated with elevated basal gastrin levels and an enhanced gastrin response to hypoglycaemia whereas in multiple system atrophy basal gastrin levels are normal, but gastrin responses to hypoglycaemia deficient.

We acknowledge the assistance of the nursing staff on Ward 5 East, NIH Clinical Center, who cared for the patients during this study. Linda Nee, M.S.W., supported the patients through their difficulties while off medication and helped to recruit subjects for the study. Miss Judy Hertler assisted in the preparation of this manuscript. 


\section{References}

I Polinsky RJ. Pharmacological responses and biochemical changes in autonomic failure. In: Bannister R. (Ed), Autonomic Failure. London. Oxford University Press. 1983:201-36.

2 Zeigler M. Lake C. Kopin I. The sympathetic nervous system defect in primary orthostatic hypotension. $N$ Engl $J$ Med 1977:296:293-7.

3 Polinsky RJ. Kopin IJ. Ebert MH. Weise V. Pharmacologic distinction of different orthostatic hypotension syndromes. Neurology 1981:31:1-7.

4 Polinsky RJ. Goldstein DS. Brown RT. Keiser HR, Kopin IJ. Decreased sympathetic neuronal uptake in idiopathic orthostatic hypotension. Ann Neurol 1985:18:48-53.

5 Polinsky RJ. Kopin IJ. Ebert MH. Weise V. The adrenal medullary response to hypoglycemia in patients with orthostatic hypotension. J Clin Endocrinol Metah 1980:51:1401-6.

6 Polinsky RJ. Kopin IJ, Ebert MH, Weise V. Recant L. Hormonal responses to hypoglycemia in orthostatic hypotension patients with adrenergic insufficiency. Life Sci 1981:29:417-25.

7 Polinsky RJ. Taylor IL. Chew P. Weise V. Kopin IJ. Pancreatic polypeptide responses to hypoglycaemia in chronic autonomic failure. J Clin Endocrinol Metab 1982:54:48-52.

8 Olefsky JM. Diabetes mellitus. In: Wyngaarden JB and Smith LH, eds, Cecil Texthook of Medicine. Philadelphia, WB Saunders. 1985:1320-41.

9 Russell RCG. Faber RG. Hobsley M. Plasma gastrin concentration related to acid secretion during insulin hypoglycaemia. Br J Surg 1977:64:470-2.

10 Gochman N. Schmitz JM. Application of a new peroxidase indicator reaction to specific automated determination of glucose with glucose oxidase. Clin Chem 1972:18:943.

11 Da Prada M. Zurcher G. Simultaneous radioenzymatic determination of plasma and tissue adrenalin. noradrenalin and dopamine within the femtomole range. Life Sci 1976:19:1161-74

12 Passon PG. Peuler JD. A simplified radiometric assay for plasma norepinephrine and epinephrine. Anal Biochem 1973;51: 618-31.

13 Weise VK. Kopin IJ. Assay of catecholamines in human plasma: studies of a single isotope radioenzymatic procedure. Life $\mathrm{Sc} i$ 1976:19:1673-86.

14 Dockray GJ. Taylor IL. Hepatodecapeptide gastrin measurement by specific radioimmunoassay. Gastroenterology 1976:71: $971-7$

15 Stern DH. Walsh JH. Gastrin release in postoperative ulcer patients: evidence for release of duodenal gastrin. Gastro- enterology 1973;64:363-9.

16 Stadil F. Effect of vagotomy on gastrin release during insulin hypoglycemia in ulcer patients. Scand $J$ Gastroenterol 1972:7:225-31.

17 Korman MG. Hawsky J, Scott PR. Serum gastrin in duodenal ulcer III. Influence of vagotomy and pylorectomy. Gut 1972:13:39-42.

18 Jaffe BM. Clendinnen BG. Clarke RJ, Williams JA. Effect of selective and proximal gastric vagotomy on serum gastrin. Gastroenterology 1974;66:944-53.

19 Lanciault G, Bonoma C. Brooks FP. Vagal stimulation, gastrin release and acid secretion in anaesthetised dogs. Am J Physiol 1973:225:546-52.

20 Taylor IL, Feldman M. Pancreatic polypeptide and the vagus. In: Rehfeld JF and Amdrup E, eds. Gastrins and the Vagus. London. Academic Press, 1979:267-71.

21 Oppenheimer D. Neuropathology of progressive autonomic failure. In: Bannister R, Ed, Autonomic Failure, London, Oxford University Press, 1983:267-83.

22 Emas S, Svensson S, Lilja B, Kaess H. Reduction of serum gastrin response to insulin hypoglycemia by selective vagotomy with pyloroplasty in duodenal ulcer patients. Surgery 1980;87:294-9.

23 Farooq $\mathrm{O}$. Walsh JH. Atropine enhances serum gastrin response to insulin in man. Gastroenterology 1975:68:662-6.

24 Brandsborg O. Brandsborg N. Lovgreen NA, Christensen NJ. Increased plasma noradrenaline and serum gastrin in patients with duodenal ulcer. Eur J Clin Invest 1978;8:11-4.

25 Stadil F, Rehfeld JF. Gastrin response to insulin after selective. highly selective, and truncal vagotomy. Gastroenterology 1974:66:7-15.

26 Stadil F. Rehfeld JF. Hypoglycemic release of gastrin in man. Scand J Gastroenterol 1972:7:509-14.

27 Brandsborg O, Christensen NJ, Lovgreen NA, Brandsborg M, Rehfeld JF. Increased sensitivity of gastrin release to adrenaline in duodenal ulcer. Gut 1978:19:202-6.

28 Stadil F. Rehfeld JF. Release of gastrin by epinephrine in man. Gastroenterology 1973;65:210-5.

29 Brandsborg O, Brandsborg M, Christensen NJ. Plasma adrenaline and serum gastrin: studies in insulin-induced hypoglycemia and after adrenaline infusions. Gastroenterology 1975:68:455-60.

30 Robertson D, Hollister AS, Carey EL, Tung C-S. Goldberg MR, Robertson RM. Increased vascular beta ${ }_{2}$-adrenoceptor responsiveness in autonomic dysfunction. $\mathrm{J} \mathrm{Am} \mathrm{Coll} \mathrm{Cardiol}$ 1984:3:850-6. 